\title{
Numerical Investigation of Natural Convection Flow in a Hexagonal Enclosure Having Vertical Fin
}

\author{
M. Fayz-Al-Asad ${ }^{1 *}$, M. M. A. Sarker ${ }^{1}$, M. J. H. Munshi ${ }^{2}$ \\ ${ }^{1}$ Department of Mathematics, Bangladesh University of Engineering and Technology \\ (BUET), Dhaka-1000, Bangladesh \\ ${ }^{2}$ Department of Mathematics, Hamdard University Bangladesh (HUB), Hamdard Nagar, \\ Gazaria, Munshigonj-1510, Bangladesh
}

Received 10 November 2018, accepted in final revised form 26 February 2019

\begin{abstract}
Numerical study of natural convection flow in a hexagonal enclosure with a single vertical fin attached to its heated bottom wall has been carried out. Finite element method based Galerkin weighted residual technique is used to solve the governing equation. The horizontal walls of the enclosure are kept at constant high temperature while the inclined walls are kept at constant cold temperature. A vertical heated fin is attached to the hot bottom wall with a length $(l)$ at a position $(h)$ from the left surface having thickness $(b)$. The Prandlt number for the flow inside the enclosure is 0.71 . The results of the problem are presented in graphical and tabular forms and discussed. The fin efficiency and temperature distribution were examined. The numerical results indicate the strong influence of the mentioned parameters on the flow structure and heat transfer as well as temperature. A set of graphical results are presented in terms of streamlines, isotherms contour, temperature profiles, velocity profiles, local Nusselt number and average Nusselt number. The obtained results indicated that the heat transfer rate increases with the increase of Rayleigh number in a hexagonal enclosure. The results are validated comparing with the published works.
\end{abstract}

Keywords: Natural Convection; Hexagonal Enclosure; Fin.

๑) 2019 JSR Publications. ISSN: 2070-0237 (Print); 2070-0245 (Online). All rights reserved. doi: http://dx.doi.org/10.3329/jsr.v11i2.38797

J. Sci. Res. 11 (2), 173-183 (2016)

\section{Introduction}

Natural convection inside a cavity with different boundary conditions has been studied extensively with and without fin in the last few decades due to its

* Corresponding author: fayzmath.buet@gmail.com 
multidimensional applications. The relevant research output has numerous applications such as solar thermal collectors, nuclear reactor technologies, cooling of nuclear reactors, double glass windows, ventilation of rooms, drying technologies, food processing and electronic cooling devices etc. In the recent past, a number of studies has been conducted to investigate the flow and heat transfer characteristics in closed cavities. Only the relevant ones are cited in this paper.

Considering these importance, a number of theoretical and experimental studies have been reported. Frederick and Valencia [1] studied numerically heat transfer in a square cavity with conducting horizontal surfaces. A conducting horizontal partition was attached to the centre of it's hot wall. It was found that increasing thermal conductivity ratio enhanced heat transfer. Shi and Khodadadi [2] investigated steady laminar natural convection heat transfer in a differentially heated square cavity due to a thin fin on the hot wall. Tasnim and collins [3] reported numerical results on natural convection heat transfer in a square cavity with a baffle on hot wall. Bilgen [4] studied numerically natural convection in cavities with a thin fin on the hot wall. Frederick and Moraga [5] studied numerically three-dimensional natural convection for air inside a cubic enclosure with a thick fin attached to the hot left wall. Ben-Nakhi and Chamaka [6] investigated numerically conjugate natural convection in a square enclosure with inclined thin fin of arbitrary length. Xu et al. [7] investigated unsteady flow and heat transfer adjacent to the sidewall wall of a differentially heated cavity with a conducting and an adiabatic fin. Sun et al. [8] reported the effect of triangular fins on mixed convection in a lid-driven cavity. $\mathrm{Xu}$ et al. [9] performed a numerical study on the effect of the fin length on natural convection flow transition in a cavity. Xu [10] conducted numerical simulation on unsteady coupled thermal layers induced by a fin on the partition of a differentially heated cavity. Elatar et al. [11] examined laminar natural convection inside square enclosure with adiabatic horizontal wall with a single horizontal fin attached to the hot wall at different positions and lengths. Ma et al. [12] studied flows and heat transfer of the transition to an unsteady state in a finned cavity for different Prandtl numbers. Chen et al. [13] carried out numerical and experimental studies of natural convection in a heated cavity with a horizontal fin on a hot side wall. Pati et al. [14] investigated the effect of pin-fin thermal performance for staggered and inline arrays at low Reynolds number. In numerical study Munshi et al. [15] studied mixed convection in a square lid-driven with internal elliptic body and constant flux heat source on the bottom wall. Nasrin [16] analyzed the aspect ratio effect of vertical lid-driven chamber having a centered conducting solid on mixed magneto convection. Effects of hydrodynamics mixed convection double lid-driven square cavity with inside elliptic heated block was investigated by Munshi et al. [17].

On the basis of the above literature review, it appears that very little work reported on the hexagonal enclosure having vertical fin. There is no study on natural convection flow in a hexagonal enclosure having vertical fin. 


\section{Physical Configuration}

The physical models under consideration numerical investigation of natural convection flow having vertical fin in a regular hexagonal enclosure. The hexagonal cavity with side length of $\mathrm{W}$ is shown in Fig. 1. The inclined walls of the enclosure are kept at a constant cold temperature $T_{c}$ while the top and bottom walls are kept at heated temperature $T_{h}\left(T_{h}>T_{c}\right)$. A heated fin of length $(l)$, thickness $(b)$ and position $(h)$ is attached to the bottom wall. The gravitational force acts in the vertically downward direction. The schematic geometry of the problem is shown in Fig. 1.

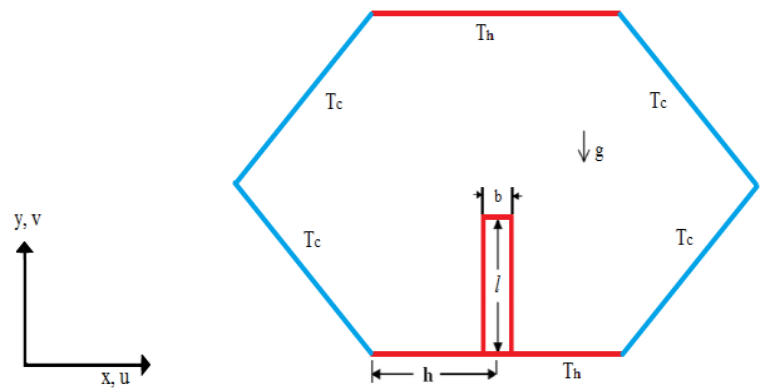

Fig. 1. Schematic diagram with boundary condition of the present problem.

\section{Mathematical Formulations}

The physical domain is shown in Fig. 1. The flow is considered steady, laminar, incompressible and two-dimensional. The radiation effect is neglected. The governing differential equations for natural convection flow using conservation of mass, momentum and energy can be written as:

$\frac{\partial u}{\partial x}+\frac{\partial v}{\partial y}=0$

$u \frac{\partial u}{\partial x}+v \frac{\partial u}{\partial y}=-\frac{1}{\rho} \frac{\partial p}{\partial x}+v\left(\frac{\partial^{2} u}{\partial x^{2}}+\frac{\partial^{2} u}{\partial y^{2}}\right)$

$u \frac{\partial v}{\partial x}+v \frac{\partial v}{\partial y}=-\frac{1}{\rho} \frac{\partial p}{\partial y}+v\left(\frac{\partial^{2} v}{\partial x^{2}}+\frac{\partial^{2} v}{\partial y^{2}}\right)+\rho g \beta\left(T-T_{c}\right)$

$u \frac{\partial T}{\partial x}+v \frac{\partial T}{\partial y}=\alpha\left(\frac{\partial^{2} T}{\partial x^{2}}+\frac{\partial^{2} T}{\partial y^{2}}\right)$

Where, $u$ and $v$ are the velocity components along $x$ and $y$ directions respectively, $p$ is the pressure, $\rho$ is the density, $\beta$ is the coefficient thermal expansion, $T$ is the temperature, $g$ is the gravitational force, $v=\frac{\mu}{\rho}=$ kinematic viscosity and $\alpha$ is the thermal diffusivity. 


\section{Boundary conditions:}

The boundary conditions for the present problem are specified as follows:

On the bottom and top walls: $u=0, v=0, T=T_{h}$

On the inclined walls: $u=0, v=0, T=T_{c}$

\section{For the Fin surface:}

$0 \leq y \leq l ; x=h+\frac{b}{2}$ and $x=h-\frac{b}{2} ; u=v=0$

Using the following dimensionless parameters, the governing equations can be converted to the dimensionless forms:

$$
\begin{gathered}
X=\frac{x}{W} ; Y=\frac{y}{W} ; U=\frac{u W}{\alpha} ; V=\frac{v W}{\alpha} ; P=\frac{p W^{2}}{\rho \alpha^{2}} ; \theta=\frac{T-T_{c}}{T_{h}-T_{c}} ; H=\frac{h}{W} ; L \\
=\frac{l}{W} \text { and } B=\frac{b}{W}
\end{gathered}
$$

By using the above dimensionless variables, the governing equations (1) - (4) in dimensionless forms are as follows:

$\frac{\partial U}{\partial X}+\frac{\partial V}{\partial Y}=0$

$U \frac{\partial U}{\partial X}+V \frac{\partial U}{\partial Y}=-\frac{\partial P}{\partial X}+\operatorname{Pr}\left(\frac{\partial^{2} U}{\partial X^{2}}+\frac{\partial^{2} U}{\partial Y^{2}}\right)$

$U \frac{\partial V}{\partial X}+V \frac{\partial V}{\partial Y}=-\frac{\partial P}{\partial X}+\operatorname{Pr}\left(\frac{\partial^{2} V}{\partial X^{2}}+\frac{\partial^{2} V}{\partial Y^{2}}\right)+\operatorname{RaPr} \theta$

$U \frac{\partial \theta}{\partial X}+V \frac{\partial \theta}{\partial Y}=\left(\frac{\partial^{2} \theta}{\partial X^{2}}+\frac{\partial^{2} \theta}{\partial Y^{2}}\right)$

In the above equations, $P r$ is the Prandtl number, $G r$ is the Grashof number and $R a$ is the Rayleigh number defined by:

$$
\operatorname{Pr}=\frac{v}{\alpha} ; \text { and } G r=\frac{g \beta\left(T_{h}-T_{c}\right) W^{3}}{v^{2}} ; R a=G r * P r
$$

The transformed boundary conditions for the equations (6) - (9) are as follows:

On the inclined walls: $U=0, V=0, \theta=0$

On the top and bottom walls: $U=0, V=0, \theta=1$

\section{For the fin surface:}

$0 \leq Y \leq L ; X=H+\frac{B}{2}$ and $X=H-\frac{B}{2} ; U=V=0$

\section{Nusselt Number}

First, the heat transfer by conduction was equated to the heat transfer by convection

$$
h^{*} \Delta T=-k \frac{\partial T}{\partial n}
$$

where $n$ is the normal distance to coordinate surface. By introducing the dimensionless variables, defined in equation (5) into equation (11), local Nusselt number is defined as:

$$
N u_{L}=-\left.\frac{\partial \theta}{\partial N}\right|_{\text {Surface }}
$$

The average Nusselt number on the cold wall is obtained as follows:

$$
N u_{a v}=-\left.\int_{2+2 L}^{3+2 L} \frac{\partial \theta}{\partial N}\right|_{\text {Surface }} d S
$$




\section{Numerical Technique}

The nonlinear governing partial differential equations, i.e., mass, momentum and energy conservation equations are transformed into a system of integral equations by using the Galerkin weighted residual method of finite-element formulation. The nonlinear algebraic equations so obtained are modified by imposition of boundary conditions. These modified nonlinear equations are transferred into linear algebraic equations with the help of Newton's method. Lastly, these linear equations are solved by applying Triangular factorization. For numerical computation and post processing, the software COMSOL Multiphysics is used.

\section{Program Validation and Comparison with Previous Work}

In order to check the accuracy of the numerical results obtained in this problem, a comparison is made between results of the average Nusselt number obtained from this study with other published results for enclosure without a fin as shown in Table 1. The maximum derivation found was $1.5 \%$ for the case of $R a=10^{6}$.

Table 1. Comparison of average Nusselt number obtained from the present study and those reported in the literature.

\begin{tabular}{lccc}
\hline Ra & $10^{4}$ & $10^{5}$ & $10^{6}$ \\
\hline Shi and Khodadadi [2] & 2.247 & 4.532 & 8.893 \\
Tasnim and Collins [3] & 2.244 & 4.524 & 8.855 \\
Elatar et al. [11] & 2.234 & 4.517 & 8.948 \\
Present result & 2.245 & 4.522 & 8.835 \\
\hline
\end{tabular}

In addition, a comparison of the streamlines and isotherms is made for the present results with those of Tasnim and Collins [3] and Elatar et al. [11] at ( $R a=10^{5}, B=0.01, L=0.5$ and $H=0.75$ ) as shown in Fig. 2. The shapes of streamline contours are almost identical. For the isotherms, one can see the strong agreement of the present results with those by Tasnim and Collins [3] and Elatar et $a l$. [11] as seen in the figure.

\section{Result and Discussion}

In this numerical analyze, the natural convection flow in a hexagonal enclosure with single vertical fin attached to its heated bottom wall has been carried out. The effect of the heat transfer inside the hexagonal enclosure is studied using the following range of values are given Rayleigh number $\left(10^{3} \leq R a \leq 10^{6}\right)$ and fin length $(L=0.20,0.35$ and 0.50$)$, fin thickness $(B=0.02)$ and fin position ( $H=0.25,0.50$ and 0.75 ) while $P r=0.71$ was considered for the flow inside the enclosure and then illustrated graphically. 

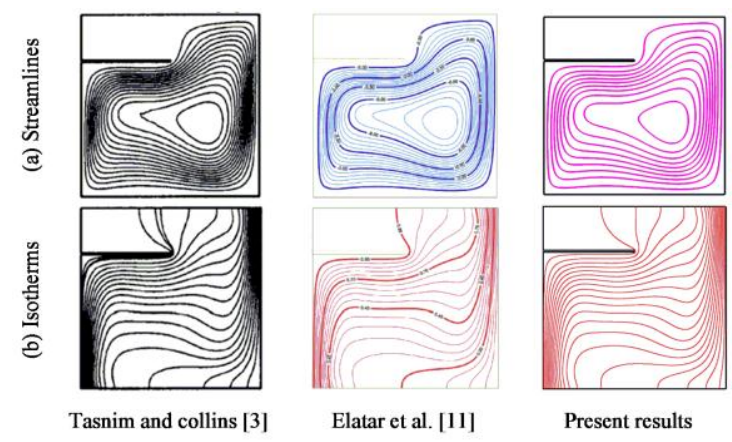

Fig. 2. Comparison of present results with Tasnim and collins [3] and Elatar et al. [11].

The results are presented in terms of streamlines in Fig. 3; isotherms in Fig. 4 and in terms of dimensional velocity profiles in Fig. 5, dimensional temperature profiles in Fig. 6 and local Nusselt number along the heated bottom wall including both fin surfaces and fin tip are shown in Fig. 7. Fig. 3 shows that the streamlines for different length and position of fin $\left(R a=10^{5}\right.$ and $\left.\operatorname{Pr}=0.71\right)$ created clockwise and counter clockwise circulation cells near the left and right side of the enclosure. When the fin length $L=0.20$, the strength of the buoyancy inside the enclosure is more significant changed. Again when fin length increases, the vortices are shifted downward and the shape of the central eddy are changed into in oval shaped. Moreover, increasing the fin length increases the strength of the buoyancy force to influence the flow field. Conduction dominant heat transfer is observed from the isotherms in Fig. 4 for Rayleigh number $R a=10^{5}$ with $\operatorname{Pr}=0.71$, different fin length $(L=0.20,0.35$ and 0.50$)$ and different fin position $(H=$ $0.25,0.50$ and 0.75$)$. It can be seen from the figure that thick thermal boundary layer exists near to the heated walls due to the different fin length and position. When the fin surface $L=0.5$ and $H=0.50$, isotherms are found to concentrate near the upper wall and both sides of the fin surface respectively and isotherm lines are bending more which means increasing heat transfer through convection. Moreover, the fin surface plays a significant role in heat transfer inside the enclosure. 

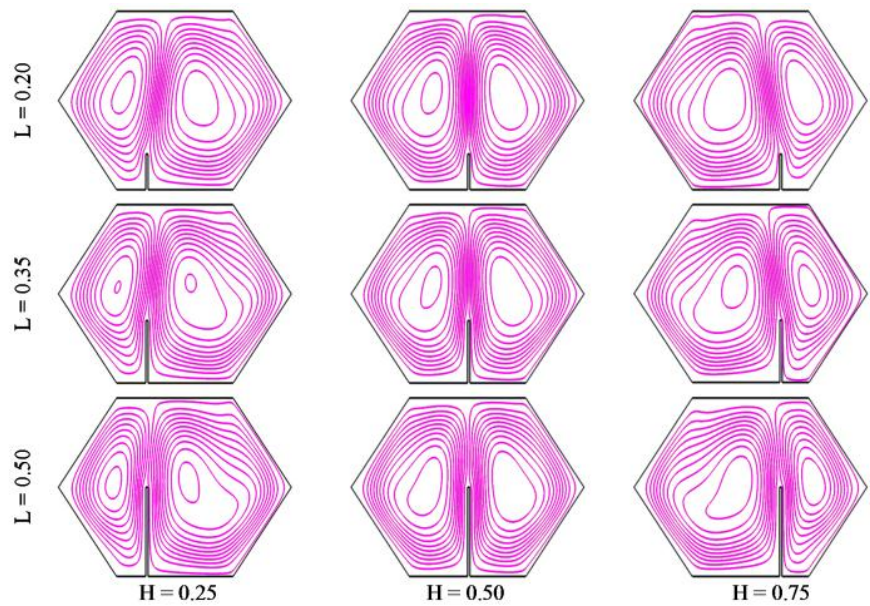

Fig. 3. Streamlines for different fin length and position at $R a=10^{5}$ and $\operatorname{Pr}=0.71$.
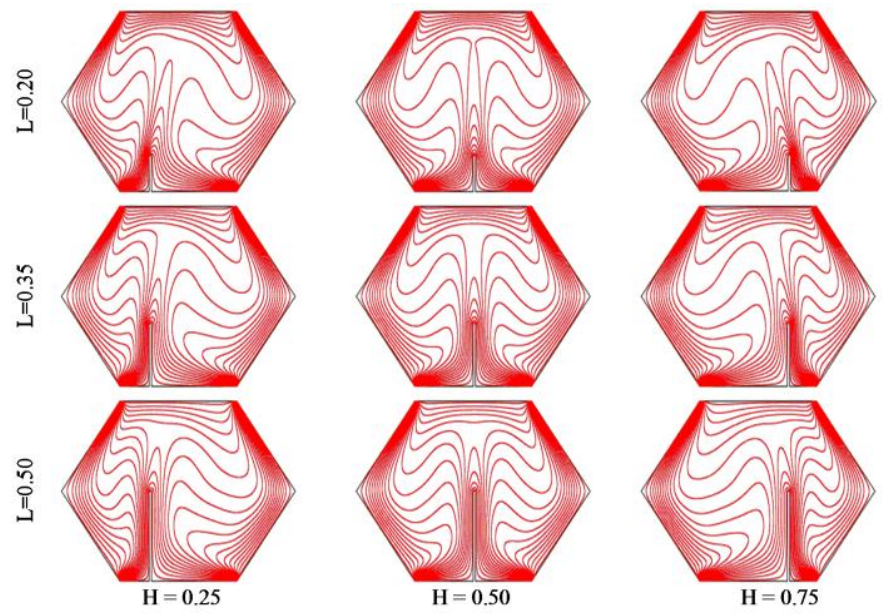

Fig. 4. Isotherms for different fin length and position at $R a=10^{5}$ and $\operatorname{Pr}=0.71$.

Variation of vertical velocity profiles along the horizontal centre line for different values of fin length $(L)$ and Rayleigh number $(R a)$ with fin position $H=0.5$ and $P r=0.71$ of enclosure is shown in Fig. 5. It can be seen that for lower values of Rayleigh number, vertical velocity profiles has smaller change but higher value of Rayleigh number, velocity profiles has larger change. Moreover, the absolute value of maximum and minimum value of velocity increases with increasing Rayleigh number. Variation of horizontal temperature profiles along the vertical centre line for values of fin position $(H)$ and Rayleigh number $R a$ with fin length $L=0.5$ and $\operatorname{Pr}=0.71$ of cavity is shown in Fig. 6. As seen from this figure 
the temperature values increases with increasing Rayleigh number inside the enclosure. The local Nusselt number distribution along the heated bottom wall including both fin surfaces and the fin tip for different values of fin position $(H)$ and Rayleigh number $(R a)$ with fin length $L=0.5$ and $\operatorname{Pr}=0.71$ of cavity is shown in Fig. 7. It can be seen that, lower value of Rayleigh number, local Nusselt number has smaller change but higher value of Rayleigh number, local Nusselt number has larger change.

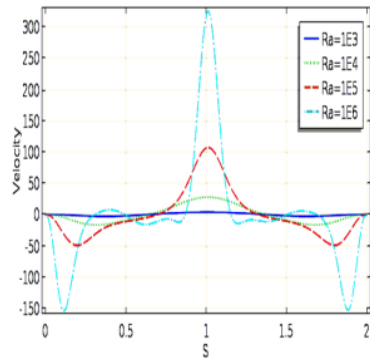

(a)

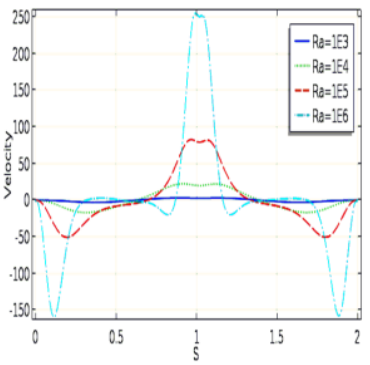

(b)

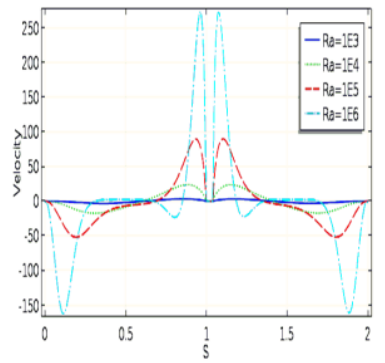

(c)

Fig. 5. Effect of variation of vertical velocity profiles with Rayleigh number for different values of fin length (a) $L=0.20$, (b) $L=0.35$ (c) $L=0.50$ and fin position $H=0.5$.

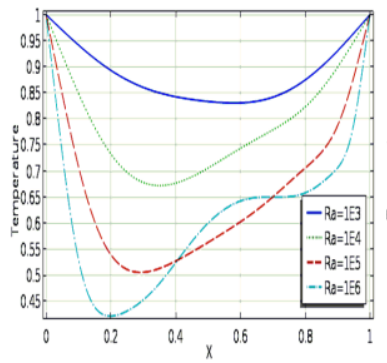

(a)

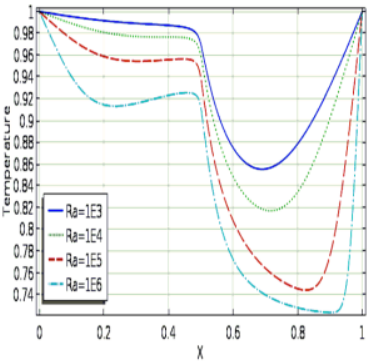

(b)

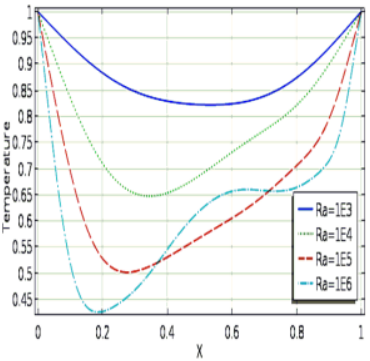

(c)

Fig. 6. Effect of variation of Temperature profiles with Rayleigh number for different values of fin position (a) $H=0.25$, (b) $H=0.50$ (c) $H=0.75$ and fin length $L=0.5$

Plot of the average Nusselt number at the top of heated wall for the effect of Rayleigh numbers $\left(10^{3} \leq R a \leq 10^{6}\right)$ with the three different values of fin length while the value of remaining parameter are kept fixed is shown in Fig. 8. The average Nusselt number increases when the value of $R a$ increases for a particular fin length. Moreover, the increasing rate of heat transfer is more enhanced for higher $R a$ with small fin length. At a constant fin length, with increase in Rayleigh number the buoyancy force increases and the heat transfer is enhanced. 


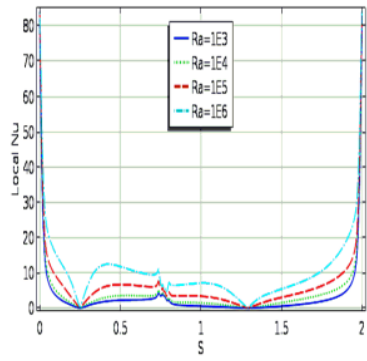

(a)

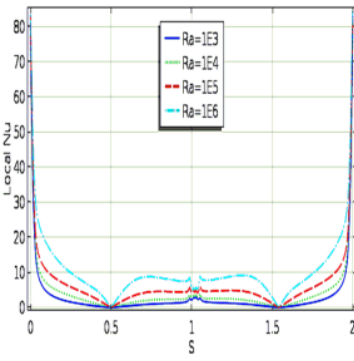

(b)

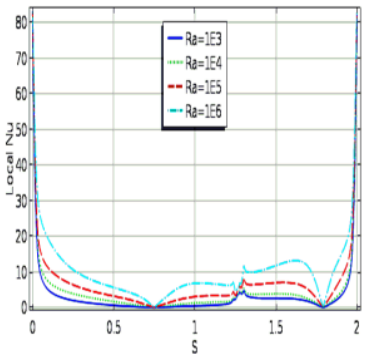

(c)

Fig. 7. Effect of variation of Local Nusselt number with Rayleigh number for different values of fin position (a) $H=0.25$, (b) $H=0.50$ (c) $H=0.75$ and fin length $L=0.5$.
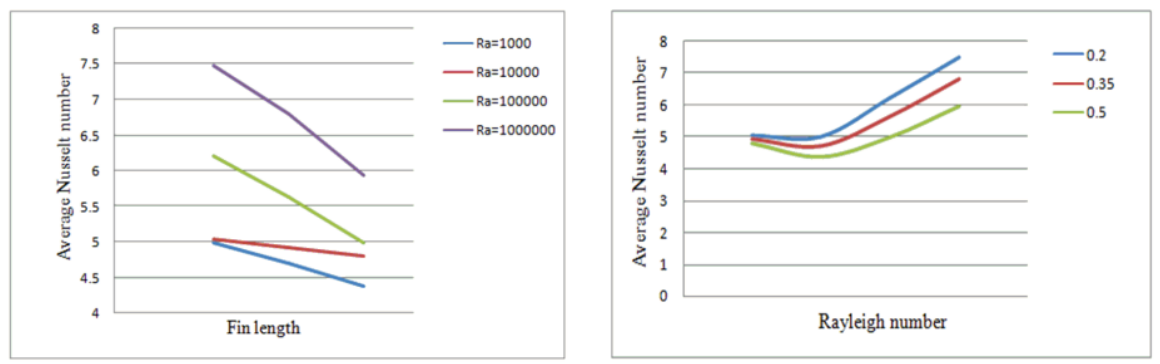

Fig. 8. Variation of the average Nusselt number of the fin length versus for different values of Rayleigh numbers $\left(10^{3} \leq R a \leq 10^{6}\right)$ while $\operatorname{Pr}=0.71$ and $H=0.5$.

\section{Conclusion}

The effect on the flow field and heat transfer behaviors for natural convection flow in a hexagonal enclosure with single vertical fin has been studied numerically. The effects of variation of fin lengths, Rayleigh number are studied. The numerical procedure was validated by comparing the streamlines, isotherms and average Nusselt number for a square enclosure obtained by the code with the existing results in the literature. Very good agreements were observed between them. The result has led to the following remarks:

- The flow field inside the enclosure has appeared to be noticeably effected by the variation of fin lengths.

- The heat transfer rate could be enhanced for greater Rayleigh number when fin length is kept constant.

- Heat transfer rate increases as fin length increases for increasing Rayleigh number.

- As fin length increases average Nusselt number also increases. In particular, high heat transfer is attained for higher Rayleigh number. 


\begin{tabular}{|c|c|c|c|}
\hline \\
\hline \multicolumn{4}{|c|}{$\mathrm{b} \quad$ fin thickness } \\
\hline B & dimensionless fin thickness & $\mathrm{u}, \mathrm{v}$ & enclosure \\
\hline g & gravitational acceleration & & velocity in $\mathrm{x}$ and $\mathrm{y}$ direction \\
\hline $\mathrm{h}^{*}$ & heat transfer coefficient & $\mathrm{U}$ & respectively \\
\hline $\mathrm{h}$ & fin position & $\mathrm{V}$ & dimensionless velocity in $\mathrm{X}$ and \\
\hline $\mathrm{H}$ & dimensionless fin position & & Y direction respectively \\
\hline $\mathrm{k}$ & thermal conductivity & $\mathrm{x}$ & horizontal coordinate \\
\hline$l$ & fin length & $\mathrm{X}$ & dimensionless horizontal \\
\hline $\mathrm{L}$ & dimensionless fin length & $\mathrm{y}$ & coordinate \\
\hline $\mathrm{n}$ & distance normal to $\mathrm{S}$ coordinate & $\mathrm{Y}$ & vertical coordinate \\
\hline $\mathrm{N}$ & $\begin{array}{l}\text { dimensionless distance normal to } \mathrm{S} \\
\text { coordinate }\end{array}$ & & dimensionless vertical coordinate \\
\hline \multirow{3}{*}{\multicolumn{2}{|c|}{$\begin{array}{ll}N u_{a v} & \text { average Nusselt number } \\
N u_{L} & \text { pral Nusselt number } \\
& \text { pressure }\end{array}$}} & \multicolumn{2}{|c|}{ Greek symbols } \\
\hline & & $\alpha$ & thermal diffusivity \\
\hline & & $\rho$ & local density \\
\hline & dimensionless pressure & $\beta$ & coefficient of thermal expansion \\
\hline $\mathrm{P}$ & Prandlt number & $\mu$ & dynamic viscosity \\
\hline \multirow{2}{*}{$\begin{array}{l}\operatorname{Pr} \\
R a\end{array}$} & Rayleigh number & v & kinematic viscosity \\
\hline & $\begin{array}{l}\text { temperature } \\
\text { dimensionless snecial coordinate }\end{array}$ & $\theta$ & dimensionless temperature \\
\hline \multirow{4}{*}{$\begin{array}{l}T \\
\mathrm{~T}\end{array}$} & along enclosure surface & \multicolumn{2}{|c|}{ Subscripts } \\
\hline & & av & average \\
\hline & & & cold \\
\hline & & $\mathrm{h}$ & hot \\
\hline
\end{tabular}

\section{Acknowledgment}

We would like to express our very great appreciation to our teachers for their willingness to support us. We also like to acknowledge the academic and technical support of Department of Mathematics, Bangladesh University of Engineering and Technology (BUET), Dhaka-1000, Bangladesh.

\section{References}

1. R. L. Frederick and A. Valencia, Int. Commun. Heat Mass Transf. 16, 347 (1989). https://doi.org/10.1016/0735-1933(89)90083-3

2. X. Shi and J. M. Khodadadi, ASME J. Heat Mass Transf. 125, 624 (2003).

3. S. H. Tasnim and M. R. Collins, Int. Commun. Heat Mass Transf. 31, 639 (2004). https://doi.org/10.1016/S0735-1933(04)00051-X

4. E. Bilgen, Int. J. Heat Mass Transf. 48, 3493 (2005). https://doi.org/10.1016/j.ijheatmasstransfer.2005.03.016

5. R. L. Frederick and S. G. Moraga, Int. J. Heat Fluid flow 28, 289 (2007). https://doi.org/10.1016/j.ijheatfluidflow.2006.03.005

6. A. Ben-Nakhi and A J. Chamkha, Int. J. Therm. Sci. 46, 467 (2007). https://doi.org/10.1016/j.ijthermalsci.2006.07.008

7. F. Xu, J. C. Patterson, and C. Lei, Int. J. Heat Fluid Flow 32, 680 (2011). https://doi.org/10.1016/j.ijheatfluidflow.2011.02.017

8. C. Sun, B. Yu, H. F. Öztop, Y. Wang, and J. Wei, Int. J. Heat Mass Transf. 54, 894, (2011). https://doi.org/10.1016/j.ijheatmasstransfer.2010.09.068 
9. F. Xu, J. C. Patterson, and C. Lei, Int. J. Therm. Sci. 70, 92 (2013). https://doi.org/10.1016/j.ijthermalsci.2013.03.012

10. F. Xu, Int. Commun. Heat Mass Transf. 67, 59 (2015). https://doi.org/10.1016/j.icheatmasstransfer.2015.07.003

11. A. Elatar, M. A. Teamah, and M. A. Hassab, Int. J. Therm. Sci. 99, 41 (2016). https://doi.org/10.1016/j.ijthermalsci.2015.08.003

12. J. Ma, F. Xu, and S. C. Saha, Int. Commun. Heat Mass Transf. 88, 220 (2017). https://doi.org/10.1016/j.icheatmasstransfer.2017.09.012

13. H. T. Chen, M. C. Lin, and J. R. Chang, Int. J. Heat Mass Transf. 124, 1217 (2018). https://doi.org/10.1016/j.ijheatmasstransfer.2018.04.046

14. B. Pati, B. Sharma, A. Palo, and R. N. Barman, Int. J. Heat Tech. 36, 697 (2018). https://doi.org/10.18280/ijht.360235

15. M. J. H. Munshi, M. A. Alim, M. Ali, and M. S. Alam, J. Sci. Res. 9, 145 (2017). https://doi.org/10.3329/jsr.v9i2.29644

16. R. Nasrin, J. Sci. Res. 3, 503 (2011). https://doi.org/10.3329/jsr.v3i3.7433

17. M. J. H. Munshi and M. A. Alim, J. Sci. Res. 9, 1 (2016). https://doi.org/10.3329/jsr.v1i1.27702 